\title{
A New Approach to ImmunoFET Operation
}

\author{
R. B. M. Schasfoort, ${ }^{a, b}$ R. P. H. Kooyman, ${ }^{a}$ P. Bergveld ${ }^{b}$ \\ \& J. Greve
}

${ }^{a}$ Department of Applied Physics, ${ }^{b}$ Department of Electrical Engineering, University of Twente, PO Box 217, 7500 AE Enschede, The Netherlands

(Received 17 February 1989; revised version received and accepted 23 May 1989)

\begin{abstract}
A new method is presented for the detection of an immunological reaction taking place in a membrane, which covers the gate area of an ISFET. By stepwise changing the electrolyte concentration of the sample solution, $a$ transient diffusion of ions through the membrane-protein layer occurs, resulting in a transient membrane potential, which is measured by the ISFET. The diffusion rate is determined by the immobile charge density in the amphoteric protein layer, which changes upon formation of antibodyantigen complexes. No membrane potential is induced at zero fixed charge density as occurs at a protein characteristic pH. Isoelectric points of embedded proteins can be determined by detecting the zero potential response.

Up to now, the authors have studied the membrane adsorption of lysozyme, human serum albumin (HSA) and the immune reaction of $H S A$ with the antibody anti-human serum albumin ( $\alpha H S A)$. The influence of protein parameters on the amplitude of the transient can be described with an empirical equation. Assuming Langmuir behaviour, the protein concentration in the solution can well be correlated with the concentration in the membrane.

This new detection method is unique concerning direct measurements of charge densities and isoelectric points of amphoteric macromolecules adsorbed in the membrane. The simple procedure of one incubation stage followed by one detection stage, without separate washing and labelling techniques, gives direct information about specific charge properties of the macromolecules to be studied.
\end{abstract}


Key words: immunoFET, isoelectric point, membrane coated ISFET, lysozyme, albumin, anti-albumin, flow through system, protein charge, biosensor.

\section{INTRODUCTION}

Many immunoassays require a relatively time-consuming analysis procedure, involving sample and reagent incubation as well as washing stages preceding an indirect measuring technique. In the last decade, simpler antibody assay methods have been proposed in which the binding of antigen to an antibody coated surface is sensed directly. A variety of optical and electronic methods for detection of specific protein binding has been developed, including the use of optical sensor devices such as plasmon resonance, reflectometry, ellipsometric techniques, all of which measure changes in refractive index profile, and capacitors (Bataillard $e t$ al., 1988) measuring changes in the dielectric constant after binding. It has also been suggested (Schenck, 1978) that FET devices can be used to detect surface polarization effects due to the formation of the antibodyantigen complex. This last detection method fails in practice because the interfacial dipole charge cannot be detected due to screening of the charges at equilibrium by small inorganic ions present in the sample (Janata, 1986).

Investigations by our group showed that in an immunological precipitate deposited on the gate of an ISFET, the specific conductivity is even higher than in the surrounding buffer, caused by a high counterion concentration in the precipitate with fixed charges (Schasfoort $e t$ al., 1989). It was concluded that the amount of protein charges in a precipitate can be measured by means of a change in local conductivity, detected with $\mathrm{AC}$ measurements. However there are some disadvantages in applying this measuring technique practically because the effect depends on the thickness of the precipitate layer which furthermore can only be measured at a controlled low ionic strength of the electrolyte and at a $\mathrm{pH}$ far from the isoelectric point. The problem can be solved by applying some dynamic disturbance to the system, such as has been described by Mattiasson and Miyabayashi (1988). Here an electrolyte flow was applied along a column, which resulted in a streaming potential. This is a measure of the amount of protein adsorbed into the column.

In this paper an alternative method for monitoring an immunological reaction occurring in a porous membrane covering an ISFET is presented, based on the measurement of membrane transient potentials induced by a sudden change in the electrolyte concentration. 


\section{DETECTION PRINCIPLE}

When a membrane separates two compartments with different electrolyte concentrations a potential gradient can be measured. The different diffusion rates of anions and cations through the membrane set up a static membrane potential, which can be expressed by the Nernst-Planck equation (Moore, 1976)

$$
\phi_{\mathrm{m}}=\frac{R T}{F} \cdot U \cdot \ln \frac{a_{2}}{a_{1}} \quad \mathrm{U}=\frac{\mathrm{D}_{+}-\mathrm{D}_{-}}{\mathrm{D}_{+}+\mathrm{D}_{-}}
$$

where $\phi_{\mathrm{m}}=$ the membrane potential, $R T$ and $F$ have their common meaning, $U=$ the ratio of the diffusion coefficients $\left(D_{+}\right.$and $\left.D_{-}\right)$of cations and anions, $a_{1}$ and $a_{2}$ are the electrolyte activities in the respective compartments. In fact, this is the system that was used by Aizawa et al., 1977, to detect immunoreactions (see Fig. 1(a)).

The mobility of ions can be influenced by the immobile charge density in the membrane and as a rule the mobility of co-ions is less favoured with respect to that of the counter-ions (Push, 1986). To account quantitatively for this effect, a more complex expression for the membrane potential gradient is required, such as that developed by Teorell, Meyer and Sievers (TMS theory) (Push, 1986). In the present paper, however, we will limit ourselves to an empirical description of the observed responses.

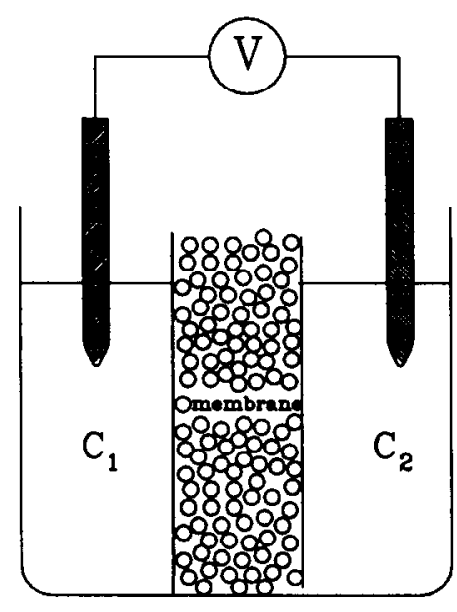

(a)

\section{ImmunoFET}

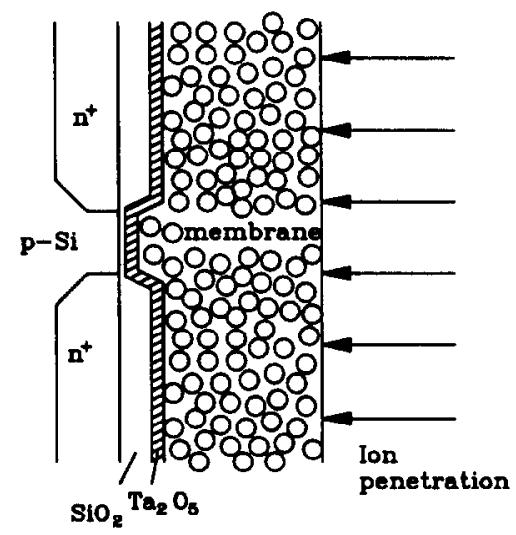

(b)

Fig. 1. Schematic representation of (a) a two-compartment system in comparison with (b) a membrane coated ISFET. 


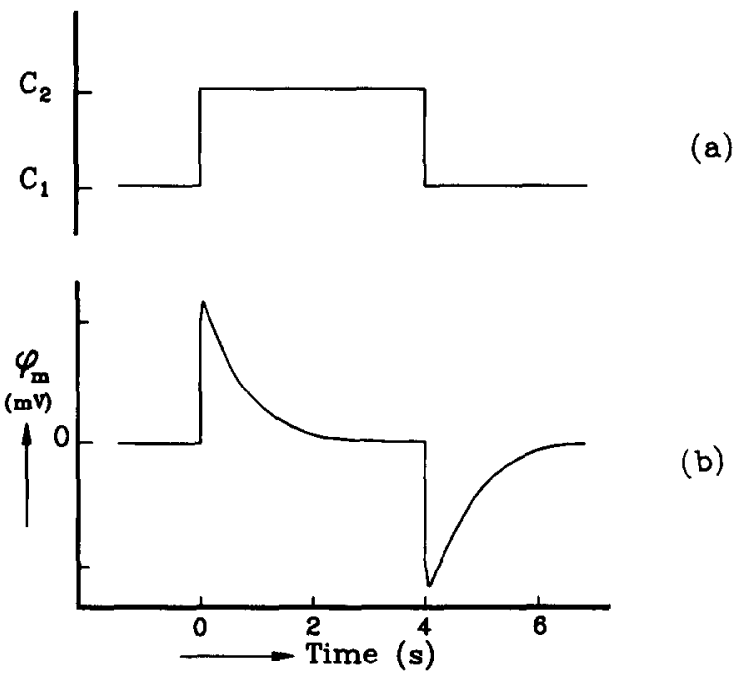

Fig. 2. The ISFET response $\phi_{\mathrm{m}}$ (b) to a stepwise concentration change (from $C_{1}$ to $C_{2}$ vice versa) (a).

A membrane coated ISFET in an electrolyte solution as represented by Fig. 1(b), can initially be considered as the above-mentioned two-compartment system. If, at one side of the membrane, a stepwise electrolyte concentration change is applied (an 'ion-step'), a transient membrane potential $\left(\phi_{\mathrm{m}}\right)$ exists, until the concentrations at both sides of the membrane are equilibrated. A typical membrane coated ISFET response due to a stepwise change in electrolyte concentration from $c_{1}$ to $c_{2}$ is shown in Fig. 2.

As in the classical two-compartment case (Fig. 1(a)), the amplitude of the transient membrane voltage, $\phi_{m}$, is a function of the difference in mobilities of the cations and anions flowing through the membrane, whereas the mobilities are functions of the membrane charge density. A protein loaded membrane will have a $\mathrm{pH}$-dependent charge density because of the amphoteric nature of the embedded proteins. This provides us with a method to modulate $\phi_{\mathrm{m}}$ in order to measure charge properties of the embedded proteins. By applying ion-steps to the system with $\mathrm{pH}$ as a parameter, $\phi_{\mathrm{m}}$ can be measured as a function of $\mathrm{pH}$. At a certain value of the $\mathrm{pH}$, which we will call the inversion point $\mathrm{pI}^{\prime}, \phi_{\mathrm{m}}$ changes sign, indicating that at $\mathrm{pH}=\mathrm{pI}^{\prime}$ no fixed charge density is present in the membrane; if the bare membrane has no intrinsic fixed charge density, the $\mathrm{pH}$ is now tuned to the isoelectric point (pI) of the protein.

In the next section we will indicate how this method can be used to find isoelectric points of proteins, and how immunoreactions can be measured. 


\section{EXPERIMENTAL APPROACH}

\subsection{General considerations}

The interface between the chemical environment and the electrical domain, the membrane, is very important; in the membrane, chemical signals must be transduced into an electrical signal. The following membrane properties must be adapted in such a way that protein adsorption can be measured:

- A controlled pore size is crucial for a reproducible membrane response.

- Immobilization of protein molecules in the interior of the membrane must be possible.

- The membrane must be well attached to the underlying substrate.

- A low or zero fixed intrinsic charge concentration of the unloaded membrane is desired.

- It is very important that no permselectivity exists, implying that at equilibrium only true $\mathrm{pH}$ values are measured with the membrane covered ISFET.

In order to measure the charge density in the membrane, we must select an ion combination which is appropriate for carrying out the experiments. Certainly the choice of a specific ion combination will influence the transient. Therefore, the experiments must be standardized with a fixed concentration of a certain salt. The salt $\mathrm{KCl}$ is a good candidate because the free mobilities of $\mathrm{K}^{+}$and $\mathrm{Cl}^{-}$in water are very similar (Moore, 1976). Deviation of the almost equal mobilities, due to the fixed charges in the membrane, then results in a transient membrane potential.

In order to find a reliable answer to the important question of which minimum shift in charge density is required to observe a significant change in inversion point $\left(\mathrm{pI}^{\prime}\right)$, two types of proteins with different isoelectric points have been used as model systems; lysozyme and human serum albumin. Under physiological conditions lysozyme is a positively charged molecule. Its isoeletric point is about 11 (Norde, 1986). If the isoelectric points of the bare membrane and adsorbing lysozyme molecule are highly different, a large effect can be expected when lysozyme adsorbs.

Next to lysozyme, human serum albumin has been used. With its isoelectric point of 4.9 (Norde, 1986), the expected shift of the inversion point obtained by adsorption on the same bare membrane is not as large as that for lysozyme. We may expect that if the contribution to the total charge is large, the larger the concentration of protein in the membrane 
will be, especially if the $\mathrm{pH}$ of the electrolyte is far from the isoelectric point of the protein. Also the charge shift per $\mathrm{pH}$ unit is of course larger with a large amount of proteins in the membrane.

Finally, the feasibility of the present method has been tested to monitor an immunoreaction. In order to detect an immunoreaction the antibody with a different isoelectric point will be captured in the antigen-loaded membrane (or vice versa), resulting in an increased protein concentration. Thus the charge shift per $\mathrm{pH}$ will increase and the inversion point will change.

\subsection{The ion-step}

A flow through system was used to carry out the experiments as schematically drawn in Fig. 3. The $\mathrm{pH}$ of the electrolyte can be changed by using a gradient vessel. When the solution flows under hydrodynamic pressure out of vessel 1, the $\mathrm{pH}$ will change through mixing with a solution of different $\mathrm{pH}$ from vessel 2 . By opening the valve for a few seconds the ISFET can be exposed to a higher salt concentration.

The step change in ion concentration is completed within $50 \mathrm{~ms}$. After $2 \mathrm{~s}$ the valve is closed and the membrane can again equilibrate with the buffer flowing out of vessel 1 . In order to exchange the electrolyte concentration very rapidly, the volume between the valve and the ISFET

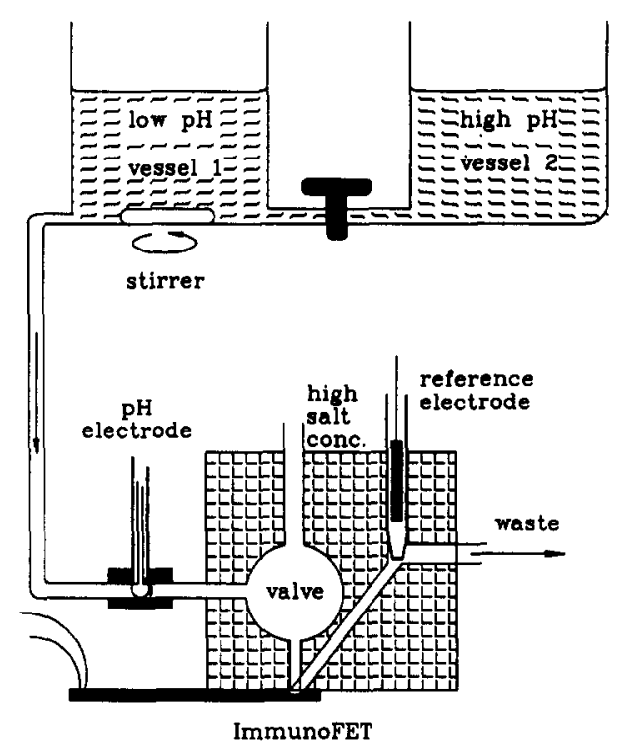

Fig. 3. Outline of the flow through system. 
was kept very small. The reference electrode has been located behind the ISFET to prevent detection of uncontrolled $\mathrm{KCl}$ leakage of the junction. Since the transients are very fast, possible long-term side effects, such as drift of the ISFET, can safely be neglected.

\section{MATERIALS AND METHODS}

The buffers used were: $10 \mathrm{~mm} \mathrm{KCl} /$ citric acid/KOH $\mathrm{pH}=3.5,10 \mathrm{~mm}$ $\mathrm{KCl} /$ acetic acid/KOH $\mathrm{pH}=5 \cdot 0$, and $10 \mathrm{mM} \mathrm{KCl} / \mathrm{morpholino}$ ethan sulphonic acid (MES) (Merck, Darmstadt, FRG)/KOH pH $=6.0$. The influence of the buffer on the conductivity of the $\mathrm{KCl}$ solution can be neglected (less than $2 \%$ ). $\mathrm{KCl}(40 \mathrm{mM})$ was used as the 'high salt' electrolyte which had a conductivity of 4.0 times the buffer conductivity. The conductivity was measured with a Consort K 812 conductivity meter. Lysozyme chloride and human serum albumin (HSA) was purchased from Sigma (St. Louis, USA), and anti human serum albumin ( $\alpha \mathrm{HSA}$ ) was from Dakopath (Denmark). The $\alpha$ HSA concentration of the polyclonal serum was defined as the titre at which full precipitate formation took place with an equimolar concentration of HSA.

For the preparation of the protein support polystyrene latex $2.5 \%$, $0.12 \mu \mathrm{m}$ (Polyscience, Warrington, USA) was mixed (1:1) with $0.25 \%$ agarose (Biorad, Richmond, California, USA) type low IEE, zero $M_{\mathrm{r}}$. The mixture was cast on a wafer containing the ISFETs with a lift-off pattern of polyimide and cooled in a refrigerator at $4^{\circ} \mathrm{C}$. This resulted in a slow evaporation of the solvent and left a porous membrane with thickness of about $5 \mu \mathrm{m}$. This thickness was measured with a surface profiler (Sloan Dektak, Santa Barbara, California, USA). SEM pictures show a pore size of approximately $0.2 \mu \mathrm{m}$. Evaporation at $4^{\circ} \mathrm{C}$ has the advantage that the agarose immobilizes the latex, resulting in a reproducibly formed membrane without internal stress. After a temperature step to $55^{\circ} \mathrm{C}$, the polyimide was removed with $\mathrm{KOH}$, lifting off the membrane at undesired places on the wafer. In this way ISFETs with a latex membrane on top of the gate area were manufactured. Proteins could be adsorbed to the support by incubation for a certain time.

The ISFETs used in the experiments were n-channel ISFETs with a $70 \mathrm{~nm}$ thermally grown $\mathrm{SiO}_{2}$ and $120 \mathrm{~nm} \mathrm{Ta} \mathrm{T}_{5}$ gate, which were connected to a source and drain follower (Bergveld, 1981). The dimensions of the chips were rather large (3-5 $\mathrm{mm}$ ) for easy encapsulation. The ISFETS were mounted on a piece of printed circuit board and encapsulated with Hy-Sol epoxy, which was flattened for leak-free mounting in a flow through system (see Fig. 3). The pH of each buffer was measured with a 
Consort $\mathrm{pH} / \mathrm{mV}$ meter. The distance between $\mathrm{pH}$ electrode and the ISFET was minimized in order to be sure to measure the actual $\mathrm{pH}$ at the ISFET. In this way direct measurement of the transient membrane potential at different $\mathrm{pH}$ values was accomplished.

\section{EXPERIMENTS}

\subsection{A typical experiment}

An ISFET with a lysozyme loaded membrane deposited on the gate was mounted in the flow through system. The $\mathrm{pH}$ dependent source gate voltage at equilibrium was the same as that observed with a bare ISFET (Schasfoort et al., 1989). By opening the valve for approximately $2 \mathrm{~s}$, a sudden change in the electrolyte concentration from $10 \mathrm{~mm}$ to $40 \mathrm{mM} \mathrm{KCl}$ was accomplished. This resulted in a transient as shown in Fig. 2 . Since the ISFET with the membrane was exposed to the unbuffered $40 \mathrm{mM} \mathrm{KCl}$ solution only for a short time without reaching equilibrium, the amplitude of the transient after the electrolyte step decrease was not important. Measuring the transient at different $\mathrm{pHs}$, the $\mathrm{pH}$ dependent membrane potentials were observed. The $\mathrm{pH}$ was slowly increased by mixing the buffers with different $\mathrm{pH}$ in the gradient vessel. During this increase the membrane coated ISFET was exposed every $45 \mathrm{~s}$ to $40 \mathrm{~mm} \mathrm{KCl}$ for $2 \mathrm{~s}$.

In Fig. 4 a typical registration is shown as the result of a pulsatile increase of the electrolyte concentration at a slowly increasing $\mathrm{pH}$. It shows an S-shaped curve on which 'spikes' are superimposed. The Sshaped curve is the result of changing the $\mathrm{pH}$ by mixing the two buffer solutions and the 'spikes' are transients caused by the ion step. At $\mathrm{pH}=\mathrm{pI}^{\prime}$ the transient is reversed; $\mathrm{pI}^{\prime}$ is specific for the total immobile charge density present in the membrane for that specific measuring condition. When a high pass filter (time constant $=3 \mathrm{~s}$ ) is used and the $\mathrm{pH}$ electrode is connected to the $\mathrm{X}$-input of an $\mathrm{X}-\mathrm{Y}$ recorder, the transient as function of $\mathrm{pH}$ is registered. Besides, the ISFET response was only measured during the 2 s of the electrolyte concentration step increase. Now, accurate detection of the inversion point $\left(\mathrm{pI}^{\prime}\right)$ as well as the slope of the $\phi_{\mathrm{m}}-\mathrm{pH}$ curve is possible. An example of this registration is shown in Fig. 5.

Strikingly, in all experiments it was observed that there is a strictly linear relationship between the membrane potential $\phi_{\mathrm{m}}$ and the $\mathrm{pH}$, with a certain $\mathrm{pI}^{\prime}$ and slope. However, the $\mathrm{pI}^{\prime}$ and the slope of the $\phi_{\mathrm{m}}-\mathrm{pH}$ curve change when the membrane composition is varied in one or another way. In the $\mathrm{pH}$ region near the inversion point for each value, two $\phi_{\mathrm{m}}$ values are 


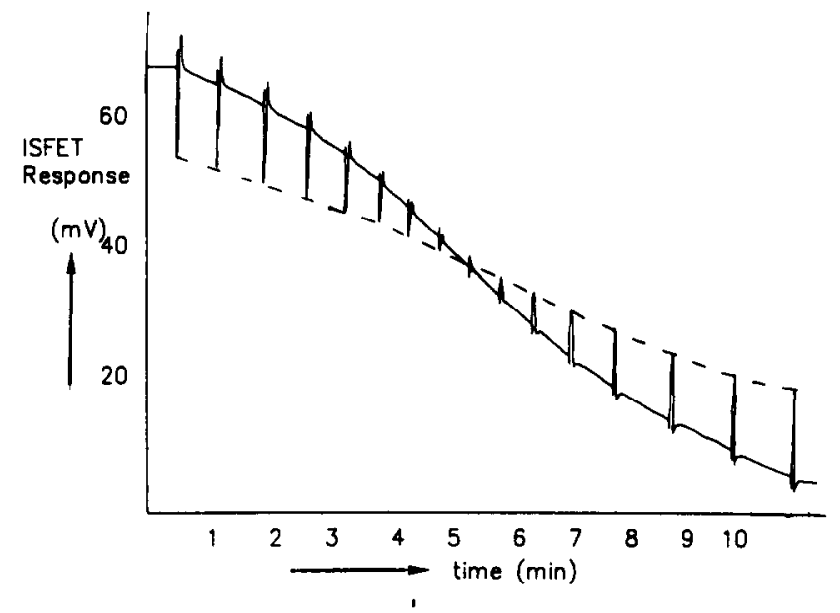

Fig. 4. Measurement of the ISFET response caused by ion-steps in a $\mathrm{pH}$ gradient as a function of time. At $t=0, \mathrm{pH}=6.5$; at $t=10 \mathrm{~min}, \mathrm{pH}=7.5$.

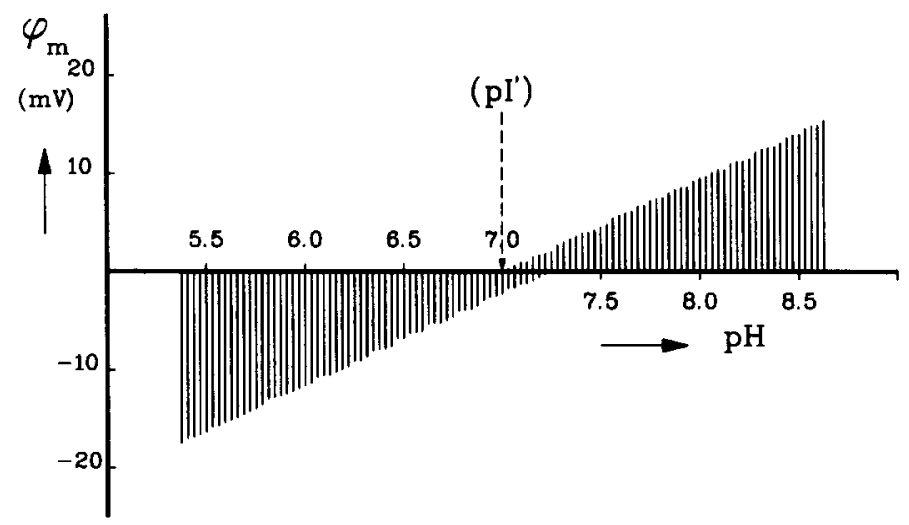

Fig. 5. Detection of the transients caused by the ion-step as a function of the $\mathrm{pH}$ of the

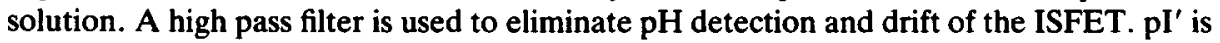
defined as the zero value of the positive transients.

found: the transients are biphasic. The width of this overlap is not always the same, probably due to inhomogeneities in the membrane. In this paper we therefore define, based on experimental reasons, the inversion point $\left(\mathrm{pI}^{\prime}\right)$ as the $\mathrm{pH}$ where the positive peak, obtained by an electrolyte step increase, is zero. (See Fig. 5.)

The relationship between membrane composition on one hand and pI' $^{\prime}$ and the slope of the $\phi_{\mathrm{m}}-\mathrm{pH}$ curve on the other, proves to be the key feature of the present detection method, as will be shown in the following. 


\subsection{The bare membrane}

A bare polystyrene-agarose membrane covered ISFET was exposed to an ion-step as a function of $\mathrm{pH}$, according to the procedure described above. As in the previous experiments, a $\mathrm{pH}$ dependent transient membrane potential was observed. The inversion point was at $\mathrm{pH}=2.05\left(\mathrm{pI}_{0}\right)$ obtained by extrapolating the $\phi_{\mathrm{m}}-\mathrm{pH}$ curve from measurements from $\mathrm{pH}=3$ to $\mathrm{pH}=5$. The slope of the linear $\phi_{\mathrm{m}}-\mathrm{pH}$ curve was $7 \mathrm{mV} / \mathrm{pH}$ (see Figs 6 and 8, curve 0 ). Apparently, the bare membrane changes the mobilities of potassium and chloride ions due to $\mathrm{pH}$-dependent negative charges, intrinsically present in the membrane. This can be caused by sulphate and carboxyl residues in the agarose, or by dissociable groups on the polystyrene bead surface. Other types of agarose were used in the preparation (Sigma A 0169, type I-A and Sigma A 4905, type VIII) but they had no influence on the transients. Also, the reduction of the agarose by $\mathrm{LiBH}_{4}$ had no effect on the observed inversion point. Therefore the low inversion point must be caused by dissociable groups on the polystryene bead surface. This assumption has been made acceptable by experiments with other types of polystyrene beads. Therefore, polystyrene beads with amino activated surfaces were also tested; now the inversion point was shifted to $\mathrm{pI}^{\prime}=7$. Furthermore the transients showed a stronger $\mathrm{pH}$ sensitivity of $9.5 \mathrm{mV} / \mathrm{pH}$, under identical experimental conditions.

From these experiments it is concluded that the observed intrinsic membrane effect originates from the charge density of the polystyrene beads. Fortunately the low inversion point is favourable for detecting protein molecules with isoelectric points higher than $2 \cdot 05$. The experiments described in this paper were all carried out with this polystyreneagarose membrane, implying that in the experimental $\mathrm{pH}$ range used, the bare membrane is always negatively charged. For reasons to be explained in section 6 , we will however consider the bare membrane as an ideal non-charged membrane loaded with an adsorbed amphoteric macromolecule with an isoelectric point of $\mathrm{pI}_{\mathrm{p}}=2 \cdot 05$.

\subsection{Lysozyme coated membrane}

The effect that different concentrations of lysozyme in the membrane have on the shift in inversion point was studied. Lysozyme can be incorporated into the membrane by means of two preparation methods:

1. Lysozyme can be mixed with polystyrene/agarose prior to ISFET coating. A homogeneously loaded membrane is the result.

2. Lysozyme can be adsorbed from a solution to a membrane coated 


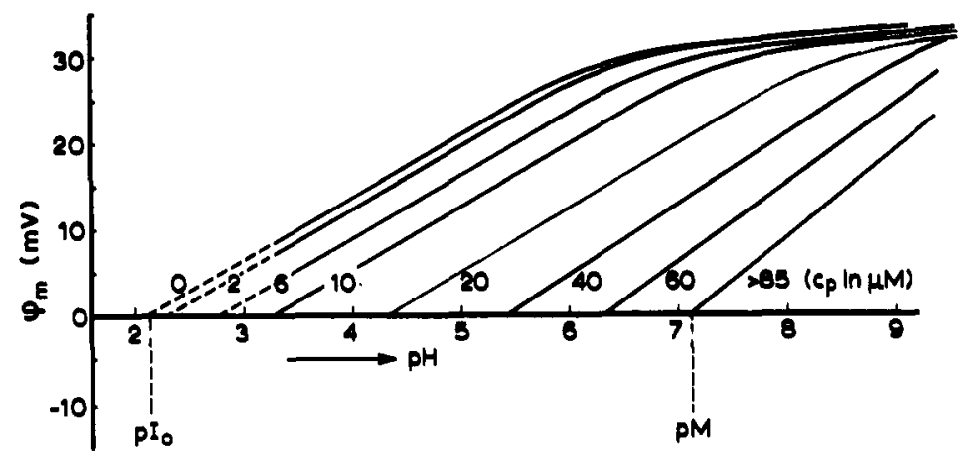

Fig. 6a. The amplitude of the positive transients $\left(\phi_{m}\right)$ such as shown in Fig. 5, as a best fit through the successive transients maxima, as a function of $\mathrm{pH}$. Different concentrations of lysozyme $\left(c_{\mathrm{p}}\right)$ in the membrane: $0,2,6,10,20,40,60,>85 \mu \mathrm{M}$ are used. For $\mathrm{pl}_{0}$ and $\mathrm{pM}$ see text.

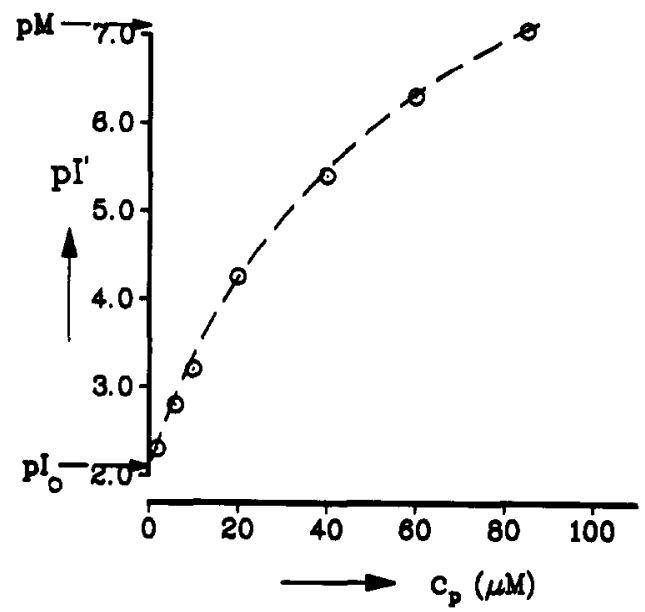

Fig. 6b. The inversion point $\left(\mathrm{pI}^{\prime}\right)$ as a function of the lysozyme concentration in the membrane $\left(c_{\mathrm{p}}\right)$ as deduced from Fig. 6(a).

ISFET. It is uncertain as to whether the lysozyme is homogeneously distributed in the membrane.

First, ISFETs with different lysozyme concentrations in the polystyrene agarose membrane were prepared according to preparation method 1. The concentrations of lysozyme in the membrane after the preparation were $0,2 \pm 1,6 \pm 1,10 \pm 2,20 \pm 2,40 \pm 4,60 \pm 4,85 \pm 5 \mu \mathrm{M}$, respectively. Each ISFET was subsequently mounted in the flow through system and the corresponding $\phi_{\mathrm{m}}-\mathrm{pH}$ curve was determined. In Fig. 6a the measured $\phi_{\mathrm{m}}$ as a function of $\mathrm{pH}$ is shown for the different lysozyme concentrations. 
Again it can be seen that a linear relationship is found between $\phi_{\mathrm{m}}$ and $\mathrm{pH}$ for $\phi_{\mathrm{m}}<25 \mathrm{mV}$. Also it can be seen that the bare membrane shows a $\mathrm{pI}^{\prime}=\mathrm{pI}_{0}$ value of 2.05. Apparently, the incorporation of a certain amount of proteins adds positive charge to the intrinsically negative charged membrane as reflected by the increase of $\mathrm{pI}^{\prime}$. In fact, the added lysozyme compensates at $\mathrm{pI}^{\prime}$ for the increasing negative charge of the bare membrane with increasing $\mathrm{pH}$. Due to the amphoteric character of proteins, the positive charge contribution of the protein to the bare membrane decreases with increasing $\mathrm{pH}$. Therefore, the necessary amount of lysozyme should increase more for the compensation of the bare membrane charge as reflected by $\mathrm{pI}^{\prime}$. This can be seen in Fig. $6 \mathrm{~b}$ where $\mathrm{pI}^{\prime}$ is plotted as a function of the concentration of lysozyme in the membrane as deduced from Fig. 6a. Note that $\mathrm{pI}^{\prime}$ is not characterizing the type of protein, but the total membrane charge density which corresponds to the concentration of adsorbed amphoteric macromolecules and bare membrane. (The meaning of $\mathrm{pM}$ is described later.)

According to preparation method 2, from the membrane covered ISFETs the initial inversion point was determined. Then the membrane coated ISFETs were immersed in lysozyme solutions having concentrations from $10^{-9} \mathrm{M}$ to $10^{-4} \mathrm{M}$ for $22 \mathrm{~h}$. After this period, the ISFETs were removed from the lysozyme solutions and allowed to equilibrate in a pure buffer solution, thus ensuring that the observed effects only originated from irreversible adsorption processes. Subsequently each ISFET was exposed to an ion-step in a $\mathrm{pH}$ gradient and the inversion point ( $\left.\mathrm{pI} \mathbf{I}^{\prime}\right)$ was determined and plotted in Fig. 7, curve (a).

The reproducibility of the results from different devices is within $0 \cdot 1 \mathrm{pH}$, whereas the detection limit for the irreversible adsorption of lysozyme to the polystyrene-agarose membrane is approximately $2 \times 10^{-9} \mathrm{M}$ after an incubation time of $22 \mathrm{~h}$. The broad dynamic range of detection is striking.

\subsection{Human serum albumin coated membrane}

ISFETs with polystyrene-agarose membranes were prepared witth different concentrations of HSA according to preparation method 1 of section 5.3. The concentrations of HSA in the membrane after the preparation were $1,2,4,8, \ldots, 512 \mu \mathrm{M}$ respectively. Each ISFET was mounted in the flow through system and using the ion step, the transients were determined as a function of $\mathrm{pH}$. The results are shown in Fig. 8.

Here we observe not only a shift of the inversion point $\mathrm{pI}^{\prime}$ as a function of the concentration but obviously also an increase of the slope $\left(\delta \phi_{\mathrm{m}} / \delta \mathrm{pH}\right)$ with increasing protein concentration in the membrane. The lines intersect 


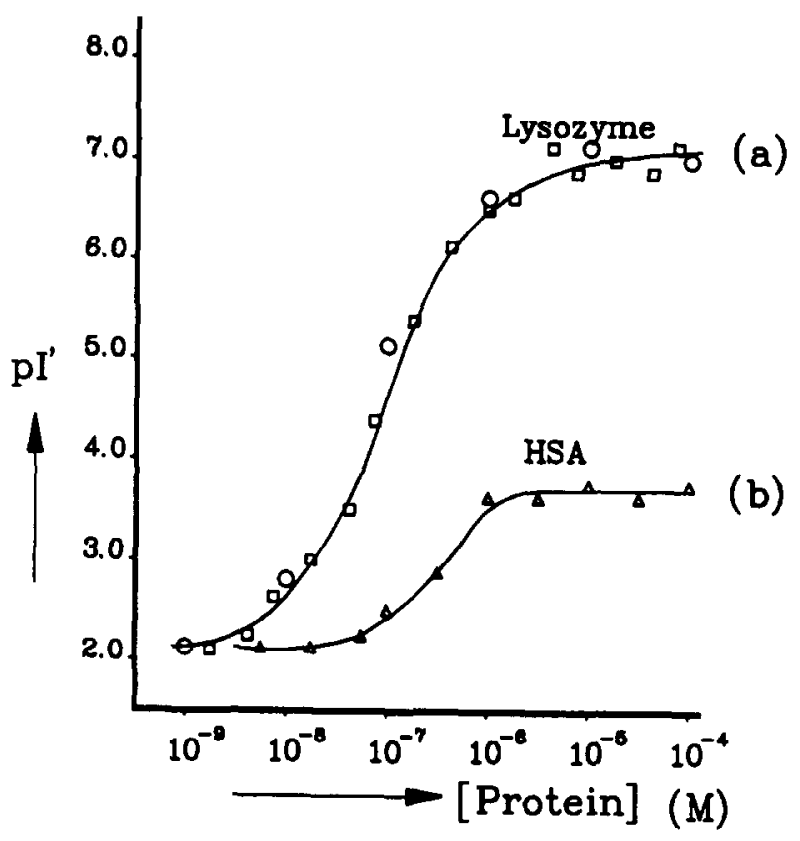

Fig. 7. The inversion point pI' as a function of different concentrations of (a) lysozyme and (b) HSA in solution after $22 \mathrm{~h}$ of incubation. In curve (a) $\square, 0$, represent different series of experiments.

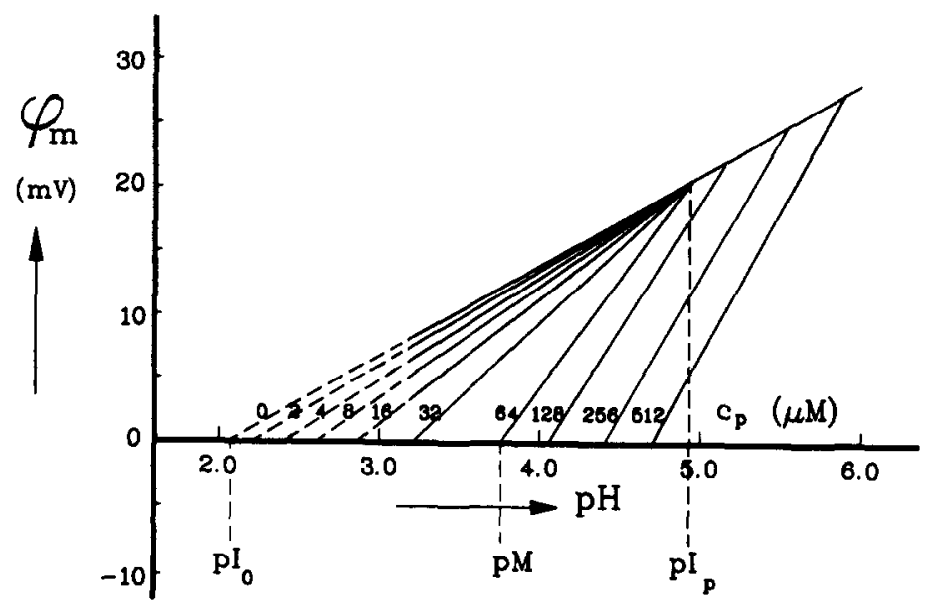

Fig. 8. The amplitude of the positive transients $\left(\phi_{\mathrm{m}}\right)$ as a function of $\mathrm{pH}$ (such as Fig. 6(a)). Different concentrations of HSA in the membrane $\left(c_{\mathrm{p}}\right): 0,2,4,8,16,32,64,128,256$ and $512 \mu \mathrm{M}$. For $\mathrm{pI}_{0}, \mathrm{pM}$ and $\mathrm{pI}_{\mathrm{p}}$ see text. 
in a hinge-point. It can be seen from Fig. 8, that at the hinge point the $\phi_{\mathrm{m}}$ is solely determined by the charge density of the bare membrane; apparently, adsorbed proteins do not contribute to the total charge density present in the membrane at this point. Membranes loaded with different concentrations of the same protein have one characteristic hinge point, which can now be identified as the isoelectric point $\mathrm{pI}_{\mathrm{p}}$ of that adsorbed protein. In this way isoelectric points of pure proteins can easily be determined as an alternative for isoelectric focusing. Note that a specific protein can thus be characterized with the observed hinge point at $\mathrm{pI}_{\mathrm{p}}$, in contrast to the inversion point $\mathrm{pI}^{\prime}$, which is not protein specific.

At concentrations in excess of $64 \mu \mathrm{M}$ HSA in the membrane, $\phi_{\mathrm{m}}$ as a function of $\mathrm{pH}$ ceases to intersect at the hinge-point due to competition of polystyrene beads and proteins in forming a texture. It is supposed that the texture of the membrane is distorted resulting in a decreased charge density of the bare membrane. Therefore the protein concentration is restricted to a maximum value, depending on the type of protein that is used. For a certain protein, with its isoelectric point $\mathrm{pI}_{\mathrm{p}}$, we can thus define a maximum inversion point $(\mathrm{pM})$ at which the slope $\left(\delta \phi_{\mathrm{m}} / \delta \mathrm{pH}\right)$ has a maximum value.

The reason why no hinge point was found with the lysozyme measurements (Fig. 6a) is due to the fact that lysozyme has a high isoelectric point $\left(\mathrm{pI}_{\mathrm{p}}=11\right)$. The lines in Fig. 6a seem to be parallel because the hinge point will have a very high value. Besides, at high $\mathrm{pH}$ values, the response of the bare membrane is not linear as a function of the $\mathrm{pH}$ anymore.

According to preparation method 2, measurements with HSA coated membrane covered ISFETs were carried out. From the bare membrane covered ISFETs the initial inversion point was determined. Then the membrane coated ISFETs were immersed in HSA solutions having concentrations from $10^{-9} \mathrm{M}$ to $10^{-4} \mathrm{M}$ for $22 \mathrm{~h}$. Subsequently, each ISFET was exposed to an ion-step in a $\mathrm{pH}$ gradient and the inversion point ( $\mathrm{pI}^{\prime}$ ) was determined and plotted in Fig. 7, curve (b). Since HSA has an isoelectric point of about $\mathrm{pH}=4.9$, adsorption of this protein to the latex membrane results in a different response as compared with lysozyme as adsorbing molecule. Due to less charge contribution per HSA molecule, the shift of the inversion point with the HSA concentration is relatively small, compared to that for lysozyme. The reproducibility of the detection of the HSA inversion points with different devices measured for a concentration of $\mathrm{HSA}$, is within $\pm 0.05 \mathrm{pH}$.

\subsection{The immunological reaction}

As an example of the measurement of an immunological reaction, the antigen-antibody couple HSA- $\alpha$ HSA was studied. ISFETs with a poly- 


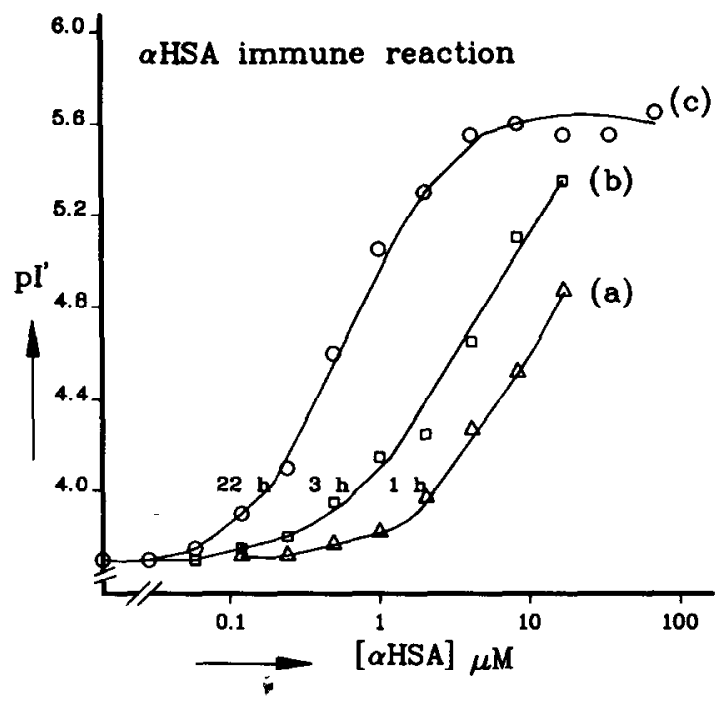

Fig. 9. Detection of the $\alpha \mathrm{HSA}-\mathrm{HSA}$ immune reaction by measuring the inversion point $\mathrm{pI}^{\prime}$ as a function of the $\alpha \mathrm{HSA}$ concentration in solution. Experimental results after (a) $1 \mathrm{~h}$ (b) $3 \mathrm{~h}$ and (c) $22 \mathrm{~h}$ of incubation, are shown.

styrene-agarose membrane were incubated with $10^{-5} \mathrm{M}$ HSA for $3 \mathrm{~h}$. The $\phi_{\mathrm{m}}$ was measured as a function of the $\mathrm{pH}$ and the inversion point was determined to be $\mathrm{pI}^{\prime}=3.72 \pm 0.05$ in accordance with Fig. 7, curve (b). Subsequently the ISFETs were incubated in different concentrations of $\alpha \mathrm{HSA}$ ranging from 0.06 to $64 \mu \mathrm{M}$. In Fig. 9 the response $\left(\mathrm{pI}^{\prime}\right)$ as a function of the protein ( $\alpha \mathrm{HSA}$ ) concentration at a specific incubation time is shown.

It can be seen that the antibody $\alpha \mathrm{HSA}$ is able to change the inversion point of the HSA coated membrane from 3.70 to 5.55 . After $1 \mathrm{~h}$ of incubation, there is already a substantial shift of $\mathrm{pI}^{\prime}$ upon reaction with $>1 \mu \mathrm{M} \alpha \mathrm{HSA}$. After $3 \mathrm{~h}$ the inversion points further increase while after $22 \mathrm{~h}$ no further shift of the inversion points was detected. It is assumed that at that time the antibody concentration in the membrane is equal to the HSA concentration. This is a rough estimation because a polyclonal anti serum was used against HSA: in such a solution a distribution exists of titration curves, molecular weights and sizes. From Fig. 9, a detection limit of $\sim 0 \cdot 1 \mu \mathrm{M} \alpha \mathrm{HSA}$ can be inferred; however, it is uncertain whether this is completely due to specific antigen-antibody interactions. Experiments with a monoclonal antibody, anti human chorion gonadotrofine $(\alpha \mathrm{HCG})$, revealed that there is at least $15 \%$ non-specific $\alpha \mathrm{HCG}$ adsorption. Although we did not minimize the non-specific binding interactions with chemicals such as polyethylene glycol, it is believed that it 
is difficult to discriminate between specific interaction and non-specific binding, on the basis of detection of charge densities alone.

\section{EXPERIMENTAL EVALUATION}

At this point it is appropriate to summarize briefly the main experimental findings.

- The inversion point $\mathrm{pI}^{\prime}$ of the $\phi_{\mathrm{m}}-\mathrm{pH}$ relation with respect to the adsorption of lysozyme and HSA, respectively, has been compared. Owing to the relative large difference of $\mathrm{pI}($ lysozyme $)-\mathrm{pI}_{0}$ as compared to $\mathrm{pI}(\mathrm{HSA})-\mathrm{pI}_{0}$, a larger effect for lysozyme than for HSA was found.

- It is concluded that the hinge point (see Fig. 8) should be identified with pI of the adsorbed protein. At this point the charge of the protein is zero and thus only the intrinsic charge of the bare membrane is measured.

- Apparently, the amplitude of the transient membrane potential is dependent on the sum of any fixed charges present in the bare membrane including those of adsorbed proteins.

- The experiments corroborate the assumption that the protein charge density near $\mathrm{pI}_{0}$ is the main quantity determining the detection limit of the present method.

- The amplitude of the membrane potential in the experiments described in this paper, never exceeds the theoretical maximum value defined by the Nernst equation $\equiv \phi_{\mathrm{m}}=R T / F \ln a_{2} / a_{1}$. With $a_{2}=40 \mathrm{~mm}$ and $a_{1}=10 \mathrm{~mm}$ (the ion-step), this maximum should be $35 \mathrm{mV}$. The reason for the never-obtained theoretical maximum value is the non-ideal permselectivity of the membrane. In other words, the co-ions are not completely excluded from the membrane.

- Linearity of the $\phi_{\mathrm{m}} / \mathrm{pH}$ relation is only found for $\left|\phi_{\mathrm{m}}\right|<2 / 3 R T / F \ln$ $a_{2} / a_{1}$. The reason for this linear behaviour around the inversion point is unclear. The authors are presently investigating this behaviour by attempting to solve the TMS-equation (Push, 1986) for membrane models that can be set up for the polystyrene-agarose matrix used in this study.

If it is assumed that a shift of more than $0 \cdot 2 \mathrm{pH}$ units from the inversion point of a bare membrane can be considered as a significant deviation from the bare membrane, the protein concentration in the membrane required for this shift is about $2 \mu \mathrm{M}$ HSA. Assuming a homogeneously charged membrane with dimensions of $(500 \times 15 \times 5)(\mu \mathrm{M})^{3}$ near the gate area, this 
corresponds to about 100 attomoles of protein molecules $\left(\simeq 10^{-16} \mathrm{Mole}\right)$. If we repeat the experiments with ISFETs incubated according to preparation method 2 of section 5.2.2, then we find a detection limit of $10^{-7} \mathrm{M}$ HSA in solution. The lower detection limit, as compared to that found for ISFETs prepared following preparation method 1 , is due to the fact that protein accumulation in the membrane can occur. Accumulation of proteins by a factor of 20 at a polystyrene surface is a normal value (Norde, 1986).

As the present method in fact measures charge density, it is more appropriate to quote the sensitivity in terms of this quantity. It is known (Norde, 1986) that HSA has $\sim 80$ unit charges at $\mathrm{pH}=2 \cdot 05$, the inversion point of the bare membrane. With a detection limit of $2 \mu \mathrm{M} \mathrm{HSA}$ in the membrane, we may conclude that the detectable charge density is thus about $10^{-4}$ charge equivalents per litre. It would be interesting to determine the net charge of other proteins at $\mathrm{pH}=2.05$ and to perform ion-step experiments on those proteins; we expect that the quoted $10^{-4}$ charge equivalents charge sensitivity is specific for the combination of membrane and electrolyte.

\section{OPERATIONAL MODEL}

Our experimental findings indicate that in a region around $\left|\phi_{\mathrm{m}}\right|<2 / 3$ $R T / F \ln a_{2} / a_{1}$, the experiments can be described by the following empirical formula:

$$
\phi_{\mathrm{m}}=\frac{R T}{F} \ln \frac{a_{2}}{a_{1}} \sum_{\mathrm{i}=0}^{\mathrm{i}=\mathrm{n}} S_{\mathrm{i}}\left(\mathrm{pH}-\mathrm{pI}_{\mathrm{i}}\right) c_{\mathrm{i}}
$$

where $\phi_{\mathrm{m}}$ is the amplitude of the transient during the ionstep; $a_{1}$ and $a_{2}$ are the electrolyte activities before and after the ion-step; $\mathrm{pI}_{\mathrm{i}}$ is the isoelectric point of a protein $i ; c_{\mathrm{i}}$ is the average concentration of protein $i$ in the membrane and is related to the degree of internal coverage, and $S_{\mathrm{i}}$ is a sensitivity factor which is a measure of the slope $\delta Q_{\mathrm{i}} / \delta \mathrm{pH}\left(Q_{\mathrm{i}}\right.$ represents the charge of protein $i$ ) which depends on the titration curve of the protein $i$, and is characteristic for this particular protein.

If the unloaded membrane has $\mathrm{pH}$-dependent dissociable groups, as is certainly the case with our polystyrene-agarose membrane, this effect can be easily included in eqn (2) by considering the membrane as an ideal non-charged membrane to which amphoteric macromolecules with $\mathrm{pI}_{\mathrm{p}}=\mathrm{pI}_{0}$, corresponding to that of the membrane, are adsorbed. The product $S_{0} \times c_{0}$ of that virtual molecule can be obtained from experiments on the bare membrane. 
In the following it will be shown how eqn (2) can be used to determine the degree of coverage in the membrane and more importantly, the protein concentration in the solution. We will concentrate on the case where only one type of protein is present in the solution; furthermore we assume that $\mathrm{pI}$ and $S$ are known. If a protein is adsorbed to the membrane the summation term is zero at the inversion point. At the maximum protein concentration in the membrane $\left(c_{m}\right)$, it can be assumed that there is $100 \%$ membrane coverage. The inversion point at this maximum concentration (pM) (see Figs 6 and 8) is characteristic for that protein. Inversion points between $\mathrm{pI}_{0}$ and $\mathrm{pM}$ indicate an incomplete coverage of the membrane. If, for such a situation, $\mathrm{pI}^{\prime}$ and $\mathrm{pM}$ are determined, then we obtain from eqn (2), applied at the inversion point $\left(\mathrm{pH}=\mathrm{pI}^{\prime}\right.$ and $\left.\phi_{\mathrm{m}}=0\right)$ :

$$
\mathrm{pI}^{\prime}=\frac{S_{0} \mathrm{pI}_{0} c_{0}+S_{\mathrm{p}} \mathrm{pI}_{\mathrm{p}} c_{\mathrm{p}}}{S_{0} c_{0}+S_{\mathrm{p}} c_{\mathrm{p}}}
$$

and

$$
\mathrm{pM}=\frac{S_{0} \mathrm{pI}_{0} c_{0}+S_{\mathrm{p}} \mathrm{pI}_{\mathrm{p}} c_{\mathrm{m}}}{S_{0} c_{0}+S_{\mathrm{p}} c_{\mathrm{m}}}
$$

Eliminating the factor $\frac{S_{0} c_{0}}{S_{\mathrm{p}}}$ in eqns (3a) and (3b), results in:

$$
\theta \equiv \frac{c_{\mathrm{p}}}{c_{\mathrm{m}}}=\left[\frac{\mathrm{pI} \mathrm{p}_{\mathrm{p}}-\mathrm{pM}}{\mathrm{pI}_{\mathrm{p}}-\mathrm{pI}^{\prime}}\right]\left[\frac{\mathrm{pI^{ \prime }}-\mathrm{pI}_{0}}{\mathrm{pM}-\mathrm{pI}_{0}}\right]
$$

where $\theta$ is the degree of coverage, $c_{\mathrm{p}}$ is the actual protein concentration in the membrane, $c_{\mathrm{m}}$ is the maximum protein concentration, $\mathrm{pI}_{\mathrm{p}}$ is the isoelectric point of protein $p, \mathrm{pI}_{0}$ is the isoelectric point of the unloaded membrane, $\mathrm{pM}$ is the inversion point at maximum protein concentration and $\mathrm{pI}^{\prime}$ is the measured inversion point.

Note that with eqn (4), we are now able to calculate the degree of coverage $\theta$ of any arbitrary protein by detecting its inversion point $\mathrm{pI}^{\prime}$, knowing its predetermined $\mathrm{pM}$ as well as the membrane $\mathrm{pI}_{0}$.

Since the porous membrane is in fact a large surface in a small volume, but so porous that we may assume that there is a negligible interaction between adsorbed molecules, we suppose that the degree of membrane coverage $\theta$ can be described by a Langmuir-type adsorption isotherm (Moore, 1976). The Langmuir isotherm describes the relation between 
coverage and protein concentration in the solution at equilibrium as follows:

$$
c_{1}=\frac{\theta}{K(1-\theta)}
$$

Here, $K$ is the Langmuir equilibrium constant and $c_{1}$ is the protein concentration in the solution.

For the corresponding graphical representation according:

$$
\frac{1}{\theta}=\frac{1}{K c_{1}}+1
$$

we can obtain $K$ from the slope of the $1 / \theta$ versus $1 / c_{1}$ line. $K$ is specific to the particular protein/membrane/electrolyte combination. For any particular membrane/protein combination a series of experiments has to be carried out as illustrated in Fig. 7 from which, by means of eqns (4) and (6), $K$ can be determined. Figure 10 shows the $1 / \theta$ versus $1 / c_{1}$ curves for the different types of proteins.

The procedure to measure an unknown protein concentration in the solution is now clear: knowing $K$, determine $\mathrm{pI}^{\prime}$, calculate $\theta$ (eqn (4)) and $c_{1}$ (eqn (6)). From Fig. 10 it can be seen that for both lysozyme and $\alpha \mathrm{HSA}$, eqn (6) is an adequate description of the adsorption behaviour, thereby

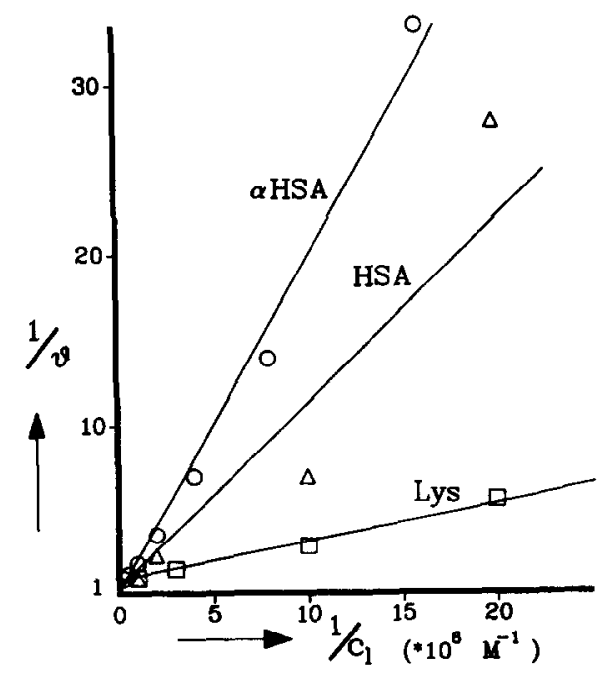

Fig. 10. The Langmuir plot for determining the Langmuir equilibrium constants $(K)$ of lysozyme adsorption ( $(\square)$, HSA adsorption $(\triangle)$ and the $\alpha \mathrm{HSA}$ immune reaction $(0)$. 
creating substantial confidence in the theoretical approach that has been followed. It is supposed that the HSA adsorption behaviour can, with some confidence, be attributed to a non-Langmuir type behaviour, and not to an invalidity of eqn (4).

From the slopes of the $1 / \theta$ versus $1 / c_{1}$, we can calculate $K_{\text {lys }}$, and $K_{\alpha \mathrm{HSA}}$ which are $3 \times 10^{6} \mathrm{M}^{-1}$ and $4 \times 10^{5} \mathrm{M}^{-1}$ respectively. The equilibrium constant for the immunological reaction seems surprisingly low, with respect to that of lysozyme adsorption and values given in the literature (Norde, 1986). This may be due to the following reasons:

(a) The polyclonal antiserum had a relatively low affinity.

(b) The assumption that the maximum $\alpha$ HSA concentration in the membrane is equivalent to the maximum HSA concentration is not true.

(c) The variety of the $\alpha$ HSA molecules in the polyclonal serum results in a range of isoelectric points and affinities.

(d) The membrane becomes less porous during the adsorption of the large $\alpha$ HSA molecules: the membrane clogs, so a concentration gradient in the membrane will occur. This is probably not the case with the relatively small lysozyme molecules.

(e) The binding of $\alpha \mathrm{HSA}$ to HSA is assumed to be measured, neglecting the dissociation of the whole immune complex from the polystyrene beads.

(f) The possibility that a significant amount of $\alpha \mathrm{HSA}$ adsorbs to the membrane or interacts non-specifically with HSA cannot be excluded on the basis of the present experiments.

\section{CONCLUSIONS}

A potentiometric method to quantify the presence of proteins in solution has been described, by exploiting both the amphoteric nature of proteins and the sensitivity of ion-mobilities to the presence of immobilized charges in a membrane. The important feature of the present method is that protein charges can be measured at rather high ionic strength of the buffer solution. Furthermore, the only function of the ISFET is to measure membrane potential gradients, implying that principally, other potentiometric electrodes can be used.

The sensitivity of the present ISFET/membrane/electrolyte combination is approximately $10^{-4}$ charge equivalents per litre, which can be expressed in protein concentrations if the titration curve of the particular protein under study is known. Up to now, the present authors have not 
attempted to optimize the system performance in this respect; it is expected that by proper choice of the ion combination/concentration step and of the membrane material, the sensitivity can significantly be improved.

It has been shown that an immunoreaction can be detected on the basis of the difference in isoelectric points of the antigen and the antigen/ antibody complex. However, to get more insight into the feasibility of the present method as a practical immunoassay, much more research is needed to select membrane materials, both to provide sufficient sensitivity and to accommodate compounds suppressing non-specific antibody interactions. Furthermore, protein incubation times, which are now approximately $20 \mathrm{~h}$, should be drastically shortened.

The combination of an empirical expression for the amplitude of the transient and the Langmuir description of protein adsorption results in a consistent description of the experimental data, as can be seen from Fig. 10. The theoretical basis of eqn (2), however, remains to be justified. As already mentioned, the TMS-theory seems an adequate tool to do so.

\section{ACKNOWLEDGEMENTS}

Ing. J. Bomer is acknowledged for the manufacturing of the flow through system, and Lian Keldermans for preparing the biochemicals. This investigation is part of the research program of the 'Stichting Fundamenteel Onderzoek der Materie (FOM)' which is financially supported by the 'Nederlandse Organisatie voor Wetenschappelijk Onderzoek (NWO)'.

\section{REFERENCES}

Aizawa, M., Kato, S. \& Suzuki, S. (1977). Immunoresponsive membrane. I. Membrane potential change associated with an immunochemical reaction between membrane-bound antigen and free antibody. J. Memb. Sci., 2, 125-32.

Bataillard, P., Gardies, F., Jaffrezic-Renault, N. \& Martelet, C. (1988). Direct Detection of Immunospecies by Capacitance Measurements. Anal. Chem., 60, 2374-9.

Bergveld, P. (1981). The operation of an ISFET as an electronic device. Sens. Actuat., 1, 17-29.

Janata, J. (1986). Chemical selectivity of field effect transistors. In Proc. of the 2nd Int. Meeting on Chemical Sensors. Ed. by J. L. Aucouturier et al., Bordeaux, France, pp. 25-31.

Mattiasson, B. \& Miyabayashi, A. (1988). Recording of the streaming potential over an affinity column in a continuous flow system as a means of quantifying proteins biospecifically. Analytica Chimica Acta, 213, 79-89. 
Moore, W. J. (1976). Physical Chemistry. Longman Group Limited, London.

Norde, W. (1986). Adsorption of Proteins from Solution at the Solid-Liquid Interface. Adv. Colloid Interface Sci. 25, 267-340.

Push, W. (1986). Measurement Techniques of Transport through Membranes, Desalination, 59, 105-98.

Schasfoort, R. B. M., Streekstra, G., Kooyman, R. P. H., Bergveld, P. \& Greve, J. (1989). Influence of an Immunological Precipitate on DC and AC Behaviour of an ISFET. Sens. Actuat., 18, 119-29.

Schenck, J. F. (1978). Technical difficulties remaining to the application of ISFET devices. In Theory, Design and Biomedical Applications of Solid State Chemical Sensors, ed. P. W. Cheung. CRC Press Inc., pp. 165-73. 